Revista Iberoamericana. Vol. LXII, Núms. 176-177, Julio-Diciembre 1996;863-873

\title{
INDIGENISMO Y LO "POSTCOLONIAL": MARIÁTEGUI FRENTE A LA ACTUAL COYUNTURA TEÓRICA*
}

POR

\author{
NEIL LARSEN \\ Northeastern Universtity
}

La mitología del concepto es siempre expresión intelectual del hecho de que los hombres no han conseguido captar un dato básico de su existencia, de cuyas consecuencias no pueden defenderse.

Georg Lukács, Historia y consciencia de clase

El reciente clamor acerca de lo "postcolonial" ha provocado un tipo de "post"-reacción ya acostumbrada: el uso del propio término se vuelve más y más inevitable al mismo tiempo que deja sospechas acerca de su real substancia - si es que la hay-intelectual y política. Sin embargo, uno de los efectos laterales indudablemente beneficiosos del fenómeno ha sido la atención renovada que el postcolonialismo ha puesto en generaciones anteriores y no-académicas de intelectuales y teóricos anti-coloniales, aun si sólo para inventar genealogías heroicas retroactivas para campeones más equívocos, del rango de Said, Spivak, Bhabha, etc. Es el nombre de Frantz Fanon que salta inmediatamente a la vista aquí, pero hay otros, largamente olvidados o ignorados fuera de los círculos más estrechos de interés histórico o regional. Entre ellos está el nombre de José Carlos Mariátegui, el gran crítico, ensayista y pensador marxista peruano de las primeras décadas del siglo.

¿Era -o es- Mariátegui un teórico "postcolonial"? Formulada de tal manera, la cuestión ya es demasiado tendenciosa para que intentemos una respuesta. Pero en la medida en que el discurso del "latinoamericanismo" continúa el proceso ya bien avanzado de asimilar las últimas vanguardias de la academia metropolitana, es obvio que a Mariátegui se le va a re-interpretar y a criticar desde esta perspectiva. ${ }^{1}$ Lo que sí importa es determinar

\footnotetext{
* Le agradezco a mi colega Róger Zapata su colaboración en la lectura crítica y en la traducción al castellano de este trabajo.

${ }^{1}$ Ver, por ejemplo, el artículo de Walter D. Mignolo, "Afterword: Human Understanding and (Latin) American Interests-The Politics and Sensibilities of Geocultural Locations" Poetics Today 16/1 (Spring, 1995) 171-214. Aquí Mignolo, al equiparar la perspectiva de Mariátegui respecto a la "dualidad de raza y espíritu" del Perú a la de Fernando Ortiz, epitomizada ésta en el concepto de la "transculturación" (181-182), efectivamente pasa por encima de la fuerte crítica que hace Mariátegui a la idea del mestizaje como síntesis cultural, por lo menos en el caso del Perú. Pero por todas sus limitaciones en cuanto a la teoría de "razas", el pensamiento de Mariátegui va mucho más allá de la teoría de la transculturación, una categoría básicamente descriptiva y formal que no contribuye a profundizar el problema de la cultura nacional en la esfera
} 
cómo y hasta qué punto una reconsideración crítica y rigurosa del pensamiento de Mariátegui en torno a cuestiones de colonialismo, liberación nacional y cultural, hibridación, etc. - las cuestiones verdaderamente sustantivas de la teoría "postcolonial", a pesar de plantearse típicamente dentro de pautas conceptuales mistificadoras - podría servir para clarificar, re-orientar y rectificar el propio "debate". Esa reconsideración es, de todos modos, el propósito de los comentarios que siguen.

Hacia el final de "El proceso de la literatura", último ensayo de la obra mejor conocida (y principal de las pocas traducidas) de Mariátegui, se escribe lo siguiente:

Y la mayor injusticia en que podría incurrir un crítico sería cualquier apresurada condena de la literatura indigenista por su falta de autoctonismo integral o la presencia, más o menos acusada en sus obras, de elementos de artificio en la interpretación o en la expresión. La literatura indigenista no puede darnos una versión rigurosamente verista del indio. Tiene que idealizarlo y estilizarlo. Tampoco puede darnos su propia ánima. Es todavía una literatura de mestizos. Por eso se llama indigenista y no indígena. Una literatura indígena, si debe venir, vendrá a su tiempo. Cuando los propios indios estén en grado de producirla. ${ }^{2}$

La distinción hecha aquí por Mariátegui es de una aparente sencillez pero impresiona por ser tan directa y de tan buen sentido en una coyuntura, como es la nuestra, en que suele reclamarse, tanto con estrépito como superficialmente, el derecho de insistir en perspectivas y lugares de expresión étnicamente "puros". Sin negarle a la cultura indígena el derecho fundamental de actuar como el más privilegiado intérprete y representativo de sí mismo, Mariátegui, sin embargo, resiste conceder legitimidad cultural y estética exclusivamente a tales auto-representaciones. Las "interpretaciones" y "expresiones" "mestizas" o noindígenas no pueden dejar de "idealizar" y "estilizar", pero esta calidad de "artificio" aun queda con el valor relativo de un preludio, históricamente necesario, de la auto-representación. El factor esencial aquí es la solidaridad del indigenista, a priori, con la causa de la sociedad, indígena, su compromiso en cuanto a su lucha por la liberación social. Esto, como Mariátegui explica con cuidado en "El proceso de la literatura" como también en "El problema del indio", es lo que diferencia al indigenismo de un "nativismo" vulgar y romantizado, cuya aparente simpatía por el "indio" se basa, no obstante, en una aprobación de las estructuras económicas y políticas que al indígena lo condenan a una condición de subalterno y explotado. ${ }^{3}$

"postcolonial" como problema dialéctico, o sea de la mediación histórica de la cultura. Este rápido, y algo incauteloso reclutamiento de Mariátegui a la recién inventada escuela "postcolonial" latinoamericana tiene el resultado antiséptico ya acostumbrado de limpiarle a Mariátegui de su marxismo.

2 "El proceso de la literatura" en Siete ensayos de interpretación de la realidad peruana (México: Ediciones Era, 1979) 306. Citado en el texto de aquí en adelante como"PL".

3 "Los 'indigenistas' auténticos - que no deben ser confundidos con los que explotan temas indígenas por mero 'exotismo'- colaboran, conscientemente o no, en una obra política y económica de reivindicación - no de restauración ni resurrección. [...] El indio no representa únicamente un tipo, un tema, un motivo, un personaje. Representa un pueblo, una raza, una tradición, un espíritu" (“PL" 304). 
Pero un examen más penetrante y crítico del pensamiento de Mariátegui aquí descubrirá algo que va más allá de la verdad ya consagrada de que alguien que vive dentro o proviene de una cultura dada la conoce y la puede representar con más verismo que él que la tiene que percebir desde afuera. Porque resulta que, al plantear la cuestión de la representación con respecto al "otro" étnico o cultural, Mariátegui cae en una especie de aporia teórica: mientras por un lado en "El proceso de la literatura" reconoce la mediación como límite (la necesidad de "idealizar y estilizar") puesto a cualquier acto de representación en relación a su objeto - un límite que, a sola excepción de las concepciones románticas más naives, sería considerado como una condición inevitable, necesaria de la representación como tal- el ensayo de Mariátegui prevé una cancelación eventual de toda mediación una vez que el objeto representado se haya iniciado como agente de su propia representación. Representaciones "artificiales" de un "ánima" "autóctona" nada más esperan y preparan el terreno para el momento en que el "ánima" pueda asumir, ella misma, esta tarea. Pero de ahí surge la cuestión: ¿qué es lo que posibilitará la eventual capacidad auto-representativa del "ánima" si está ahora ausente? ¿Y cómo se puede afirmar que tal "ánima" no está capacitada ya para "interpretar y expresar" a sí mismo? ¿Qué sucede si -como de hecho sugeriría un conocimiento mejor informado y más comprehensivo de la cultura indígena andina como lo que le fue disponible a Mariátegui en los años veinte-la cultura indígena realmente ni necesita ni necesitaba la intervención mediadora del indigenista para lograr "una versión rigurosamente verista del indio"?

La vulnerabilidad de Mariátegui a tales líneas de cuestionamiento teórico y ético, su disposición incondicional de reclutar al "subalterno" para proyectos emancipatorios que sólo después — ¿pero cómo y cuándo? - se vuelven auto-emancipatorios, etc., quizás ya bastan para descalificarlo, sea para bien o para mal, como teórico "postcolonial", terminando así de golpe nuestra discusión. Pero como ya se ha notado, la disposición a "esencializar" y al mismo tiempo hablar "por" (es decir, en lugar de) un "otro" indígena asume, ella misma, una forma paradójica en el indigenismo de Mariátegui, en tanto que meramente se anexa como especie de profecía a una teorización ya consciente y actualizada de la representación como mediación - teorización con la cual el "esencialismo" de Mariátegui entra en conflicto lógico. El pensamiento de Mariátegui, es decir, pone al revés lo que uno consideraría como la procedencia típica que va desde una estética romántica de comunión directa e inmediata (una literatura que nos da su propia "ánima”, o la de un pueblo) a una estética más sofisticada y reflexionada, basada en un proceso mediado — constitutivo de, si a la vez constituido por el "ánima"- de comunicación. En Mariátegui es el último paso que aparece como necesariamente, e infelizmente, preliminar a lo que, en última instancia y per hiatem irrationalem, vendrá a ser una condición pre-representacional de "autoctonismo integral". Una intuición estética surgida bajo la égida dialéctica de lo concreto y lo mediado -y que demuestra claramente la formación filosófica marxista y (vía Croce) hegeliana de Mariátegui- se desplaza de manera abrupta hacia el principio neo-romántico, cuando no vanguardista, de la experiencia estética como absoluto momento de —como dijo Walter Benjamin, refiriéndose al surrealismo- "iluminación profana".

La misma apariencia de paradoja - algo así como la historia de un regreso a un lugar nunca antes visitado - surge repetidamente a lo largo de "El proceso de la literatura", asumiendo a veces una forma estilística que hasta se reconoce como "mariateguiana". "La 
literatura nacional es en el Perú, como la nacionalidad misma" dice Mariátegui "de irrenunciable filiación española" (209). El Inca Garcilaso de la Vega es celebrado por Mariátegui como "el primer peruano, sin dejar de ser español" (211). Existe el Perú, o la "peruanidad", pero únicamente como un postulado abstracto, cuyo real contenido no puede desquitarse de la no- o la anti-"peruanidad" que lo subyace como punto de origen. En efecto, el "Perú" mismo puede captarse sólo como una paradoja histórica, más específicamente como forma que carece de su propio contenido orgánico, y que necesita, para compensar esta falta, encontrar el modo de crear este contenido orgánico a base de su propio ser formal y "artificial". Hasta podríamos pensar en "El proceso de la literatura", desde este ángulo, como el proyecto paradójico de escribir una historia literaria peruana que, propiamente dicho-i.e., como literatura nacional -todavía no existe.

Como "postcolonialistas", nuestro primer instinto teórico es de reconocer, y hasta de reafirmar en tal paradoja la misma condición — dentro de la cual estarán inscritas las únicas posibilidades emancipatorias que pudiera ofrecer- de lo "postcolonial" - su "founding catachresis" en palabras de Spivak. ${ }^{4}$ Pero Mariátegui ni por un momento se conforma con semejante idea. (Lo más probable es que Mariátegui la habría considerado como una broma intelectual un poco rara.) Existe, para Mariátegui, un modo de salir de esta paradoja, un modo de restaurarles su relación apropiada a forma y contenido, pasado y presente, etc. y éste es el mismo indigenismo, tanto como proyecto político y como proyecto cultural. He aquí, en el primero de los casos, la teoría, popularizada por Mariátegui, del socialismo incaico, la cual sostiene la posibilidad de una transición directa entre el aún vigente comunismo primitivo del indígena campesinado andino y el socialismo en su forma (para Mariátegui la de los inicios del sistema soviético) moderna:

¿Por qué ha de ser el pueblo incaico, que construyó el más desarrollado y armónico sistema comunista, el único insensible a la emoción mundial [del socialismo revolucionario]? La consanguinidad del movimiento indigenista con las corrientes revolucionarias mundiales es demasiado evidente para que precise de documentarla. ${ }^{5}$

Ésta desde luego no deja de ser una teoría sumamente controversial tanto en los países andinos como en el resto de la "América indígena" (Guatemala, Chiapas, etc.), debido sobre todo a la manera en que "agarró a las masas" durante la reciente insurgencia del Sendero Luminoso en el Perú.

Pero es el indigenismo como proyecto cultural lo que principalmente nos importa aquí. Mariátegui propone lo que es en efecto una teoría de la cultura andina indígena como cultura nacional embriónica, una cultura "nacional" sin nación correspondiendo a lo que ya hemos visto como una "nación" a falta de su propia cultura nacional, el Perú sin la "peruanidad". Sólo hace falta juntar estos dos polos para "peruanizar al Perú." "La nueva peruanidad es una cosa por crear. Su cimiento histórico tiene que ser indígena." ("PL"227; énfasis mío) De hecho, el indigenismo politico y el cultural coinciden aquí en torno a la formación nacional

\footnotetext{
${ }^{4}$ Gayatri Chakravorty Spivak, Outside in the Teaching Machine (New York: Routledge, 1993) 60 .
}

5 "El problema del indio" Siete ensayos, 322. 
como meta común. En ambos casos es el "cimiento histórico" de un contenido cultural incaico, orgánico y autóctono lo que sólo tiene que ser derramado en el hueco hispano-criollo del Perú para alcanzar la unidad efectiva y vital de la forma y el contenido.

Así que es la categoría histórico-filosófica de la nación la que constituye, para Mariátegui, el terreno de toda posible síntesis de forma y contenido culturales, y la que, una vezrealizada históricamente, eliminará la diferenciación todavíanecesaria entre lo "artificial" y lo "autóctono", lo indigenista y lo indígena. Pero de nuevo surge aquí una paradoja.

Para mejor captarla, sin embargo, hace falta, si sólo brevemente, revisar el problema particular que representa la nación para la filosofia, sobre todo para la filosofía racionalista del iluminismo europeo. Porque las naciones no son, por lo visto, entitades muy racionales. El nacionalismo parecería un fenómeno arraigado en las pasiones, y el amor por la "patria" algo necesariamente ligado al odio por la "patria" de otro — esto cuando la "razón" obligaría a un amor trascendente por la humanidad universal en su condición natural, y no por uno u otro segmento accidental de ella. Para Rousseau, la nación sólo podría ser racionalizada en la medida que su existencia expresara la "voluntad general"' de sus ciudadanos, algo que Kant, de manera más sistemática, designó como un "estado de derecho". ${ }^{7}$ Ninguno de los dos, sin embargo, pudo resolver el dilema de cómo, sin faltar a la razón, adjudicar entre la "voluntad general" de dos naciones distintas cuando, por ejemplo, se encontraban en estado de guerra. Porque dos "voluntades generales" o "estados de derecho" que se oponen parecerían, a virtud de esa misma oposición, sacrificar los atributos universales de lo "general" y el "derecho". Aquí la razón de Rousseau y Kant se topó con una barrera aparentemente insuperable. Al final no se podía negar que la nación no correspondía a un "estado de la naturaleza" sea en su instancia original o restaurada, sino que pertenecía al interludio de la no-razón que las separaba —eso, cuando el filósofo racionalista no dejaba atrás oportunamente sus principios universalistas en caso que los intereses nacionales peligraran. Pensemos aquí en el consejo de Rousseau al gobierno de Polonia: "tengan cuidado de que ningún polaco sea capaz de volverse ruso". ${ }^{8}$

Fue la Iluminación alemana post-Kantiana, culminando en Hegel, la que descubrió la solución filosófica a este enigma, al hallar el principio de la razón dentro de la historia misma. Si las naciones no eran en sí mismas entidades racionales, sí podrían, como entidades históricas, realizar la tarea de la razón al constituirse como el espacio o medio concreto por el cual pasaría el progreso hacia un telos racional. Esta solución se presentó, como muy bien se sabe, en la forma consumadamente irracional de la mitología eurocentrista, e.g., la apoteosis de la monarquía constitucional prusiana promulgada por Hegel, o su notoria designación del mundo más allá de la Europa occidental moderna como compuesto de "pueblos sin historia". Evidentemene no todas las naciones podían realizar simultáneamente la tarea de la razón. Tales mitos, desprovistos de su contenido filosófico y dialéctico, pronto serían inculcados tanto a los agentes como a las víctimas del colonialismo europeo. Pero, en plena consciencia de esta ironía, no hay que perder de vista el avance teórico enorme que hizo posible esta innovación

\footnotetext{
6 Ver (en traducción inglesa) "The Geneva Manuscript" en The Nationalism Reader Omar Dahbour y Micheline R. Ishay, eds. (Atlantic Highlands: Humanities Press, 1995) 22-25.

7 Ver (en traducción inglesa) The Metaphysics of Morals en The Nationalism Reader 38-47.

8 Ver "The Government of Poland" The Nationalism Reader 31, traducción mía.
} 
conceptual al simplemente comprender la dialéctica de la forma y el contenido como en sí misma resultado de un proceso histórico. La paradoja que enfrentaba a Rousseau y a Kant —cómo reconciliar la racionalidad universal de la "voluntad general" o de un "estado de derecho" con el carácter irreduciblemente irracional y particularista de las naciones-es resuelta metodológicamente en el concepto de la nación como forma históricamente necesaria -y de esta manera racional - de la "voluntad general", etc. Sólo desde esta perspectiva metodológica pudieron Marx y Engels proceder a postular la clase social en vez de la nación -concretamente, el proletariado internacional-como el portador verdaderamente objetivo de la racionalidad histórica.

Mariátegui, que asimila esta perspectiva histórico-filosófica sobre la cuestión nacional por sus lecturas de Marx y Engels y su conocimiento de la historiografía literaria y filosofía social italianas (e.g., De Sanctis y Croce) no es el primer pensador latinoamericano que probó sus ramificaciones locales. Ideólogos "románticos" desde por lo menos Sarmiento ya habían sido orientados, aunque de manera cruda, por una versión de ella. En este caso, sin embargo, la teoría de la nación como forma o mediación histórico-racional invariablemente sirve para confirmar sus superficiales tendencias eurocentristas. Siendo Europa la sede de la Razón Universal en la Historia, entonces las nuevas naciones de América Latina, si iban a realizar su propia forma esencialmente racional, tendrían que volverse "racionales", es decir, europeas, en el contenido también.

Pero Mariátegui bien puede haber sido el primero en acercarse al problema históricoracional de la nación en América Latina - y aquí, claro, su marxismo se impone como decisivo-desde la perspectiva social de la mayoría oprimida. El principio racional por actualizarse en las naciones latinoamericanas recientemente "liberadas" pero aún no realizadas históricamente ya no se identifica con alguna noción abstracta de "civilización", "progreso" o "modernidad" sino con las potencias sociales de desarrollo encerradas dentro de la corteza irracional, pseudo-europea y meramente "política" de las nuevas "repúblicas". De nuevo, la nación es destinada a dar forma concreta y necesaria a un contenido racional y universal. Pero ésta ya no es una racionalidad que presupone una asimilación a la "civilización" ya alcanzada por la metropoli del colonizador. Por el contrario, presupone la negación y superación sociales de la misma relación colonial y neo-colonial.

Una comparación con Martí se vuelve altamente ilustrativa desde esta perspectiva, puesto que Martí, anticipando a Mariátegui desde la generación previa, también había roto con el pseudo-iluminismo de las elites latinoamericanas, castigándolas, con elocuencia incomparable, por su servilismo filosófico y social. Pero a pesar de su defensa intachable (y fundamentalmente jacobinista) de una Latinoamérica plebeya y de sus constantes evocaciones de la super-nación o patria grande de "Nuestra América", Martí no podía ir más allá de una posición pre-dialéctica que identificaba la nación en su forma racional con un retorno - históricamente inexplicable - a un estado de la naturaleza. (Ver, por ejemplo, su celebración del hombre "natural" en contra del "artificial", en "Nuestra América"). Sólo podía proyectar la unidad deseada entre forma y contenido nacionales como la restauración de una esencia natural, "artificialmente" corrompida por la "civilización" del colonizador.

Y sin embargo, Mariátegui, justo al traspasar el mito romántico-liberal de la "peruanidad", se halla enfrente a un obstáculo en ruta a lo que debería ser su alternativa radicalmente historizada, es decir, propiamente dialéctica. La nación, de acuerdo a la 
perspectiva ampliamente hegeliana, le da forma concreta a un contenido - lenguaje, cultura, modos y costumbres, etc. - que la antecede históricamente. La forma brota, en un sentido histórico, del contenido. Pero el Perú parece darle la vuelta a esta dialéctica, porque en este caso lo que habrotado de la historia, como resultado de las guerras de la independencia de inicios del siglo XIX, es la forma abstracta de la nación, y no el contenido orgánico que debería haber actuado como su substrato orgánico. Como en el caso de la literatura, nos enfrentamos de nuevo con la paradoja de una forma obligada a crear su propio contenido, como se diría, ex nihilo. Sólo que ahora no es únicamente la literatura nacional que precisa ser sintetizada por medio de prestarse - o apropiarse de - el contenido de otra, pre-nacional, sino la nación en su totalidad la que no puede evitar la necesidad de una auto-creación. Y esto, a su vez, implica que el "espíritu" histórico y objetivo, o el Volksgeist que, como elemento de la dialéctica hegeliana, se concretiza o mediatiza en forma de la nación, de alguna manera puede ser dirigida conscientemente —es decir, subjetivamente- hacia este fin. El acercamiento dialéctico a la historia como el medio dentro del cual reconciliar el proyecto nacional con las demandas de la razón tiene que buscar un lugar fuera de la historia para que la dialéctica misma alcance su fruición. Puesto que la historia misma del Perú se inicia en un acto inorgánico de colonización, resulta que ella también —como la literatura del indigenismo - tiene que partir del plano de lo inorgánico para poder volverse objeto de un desarrollo histórico orgánico y "autóctono". La nación como lo históricamente concreto precisa ser históricamente "cimentada".

¿Cómo llevar esto a cabo? La respuesta de Mariátegui es aquí otra vez el recurso a un proceso preliminar de "idealizar y estilizar", es decir, una política de puros medios artificiales, o del mito. "La nación misma" como escribe Mariátegui casi al principio de "El proceso de la literatura" "es una abstracción, una alegoría, un mito, que no corresponde a una realidad constante y precisa, científicamente determinable"'(210). Es cierto que Mariátegui inicialmente propone esto como una crítica, materialista en espíritu, del historicismoliterario romántico del siglo XIX, historicismo cuyas tendencias mistificadoras (ya latentes en la categoría de Volksgeist) al desprenderse de su contexto dialéctico, se habían solidificado en una serie de esencias nacionales positivizadas, cada una con su propia "historia" oficial. Como un "postcolonizado", Mariátegui ocupa una posición especialmente favorable al desenmascaramiento del mito romántico nacionalista, puesto que los orígenes coloniales relativamente recientes del Perú vuelven transparente lo históricamente "construido" ("alegoría", "abstracción") de una nación que, poniendo el caso de Alemania o Italia, por ejemplo, más fácilmente se convence de sus orígenes pre-históricos en un brumoso bosque nórdico o en una épica virgiliana. Aquí Mariátegui de hecho anticipa una intuición críticala nación como "narración"- que, como veremos más adelante, se ha vuelto una de las signaturas de la teoría "postcolonial".

Pero - y con esto terminan las afinidades de Mariátegui y el postcolonialismo- las mismas condiciones socio-históricas que han hecho transparente el mito abstracto y alegórico de la nación para el intelectual anti-colonial son, para Mariátegui, condiciones que simultáneamente hacen necesario un acto de fe en ese mismo mito. Un contenido histórico puede, por lo menos en teoría, convertirse dialécticamente en su correspondiente forma a través de un proceso estrictamente espontáneo e inconsciente, en cuanto que un tal contenido - compuesto él mismo por prácticas dinámicas y auto-actualizantes, desde la misma producción material hasta el lenguaje - ya contiene su propia fuerza motriz, su 
propio principio de desarrollo. Una consciencia de este proceso surge, si es que tiene que surgir solamente post festum. Pero el revés de esto - una forma histórica (el Perú) que sólo se puede completar y preservar por crear (o prestarse) su propio contenido sintético-parte de un estado de ruptura y estaticismo históricos y por eso precisa actuar conscientemente para insertar una fuente exterior de contenido auto-actualizante dentro de la forma históricamente pre-existente. Y puesto que, en el caso del Perú, esta fuente yace en una sociedad indígena, de vestigios tribales y marginalizada por las instituciones de la nación abstracto-formal sociedad a falta de un motivo o interés espontáneo en hacer el papel histórico que supuestamente le corresponde- hay que buscar la manera de introducir esta consciencia "desde fuera". Es decir, para que el "indio" sirva de "cimiento histórico", es necesario que algo o alguien coloque los fragmentos a ser "cimentados". Por eso el recurso al mito, la forma de creencia consciente presumiblemente más apropiada a una cultura pre-moderna. Al "salto de fe" implícita en la creencia mítica (por lo menos como ésta es entendida por ojos modernos y racionalizantes) se le asigna la tarea de cerrar el abismo histórico entre forma y contenido.

Y así resulta que por fin Mariátegui precisa recurrir a fuentes filosóficas explícitamente irracionalistas para encontrar una solución teórica al problema paradójico de "crear", de una forma abstracta y pre-existente, el contenido que le debería haber correspondido. Hegel y Marx tienen que ser suplementados por Nietzsche, Bergson y Sorel. El hecho de ser un Perú revolucionario y socialista, o el mismo marxismo el objeto de esta fe mítica no le quita nada de la orientación fundamentalmente irracionalista al pensamiento de Mariátegui al darse este paso. Además, el mismo Mariátegui no hace ningún esfuerzo para disfrazar este recurso aparentemente necesario a lo irracional. Como escribe en su discusión crítica del ateísmo militante de González Prada en "El proceso de la literatura", “... una revolución es siempre religiosa"aún si en este sentido "sirve para algo más que para designar un rito o una iglesia" ("PL" 236). La revolución, es decir, aunque objetivamente racional, tiene que manifestarse subjetivamente en la forma de un mito. Hasta el mismo González Prada, a pesar de que inconscientemente, comprueba esta necesidad, puesto que en su caso - y hay que fijarse aquí de nuevo en la figura discursiva de la paradoja que es tan típica de "El proceso de la literatura"- el propio ateísmo se ha vuelto "religioso" (ibid.).

Pero por decisivo que haya sido — quizás de manera imprevista-al legado subsiguiente de Mariátegui (otra vez, se piensa en el caso de Sendero), este último paso a lo irracional nos importa menos aquí por lo que es en sí que por la "problemática" de la cual se desprende. Porque la política del mito sirve de "solución" a un problema que en su concepción no se desvincula de una perspectiva historicista y racional. Esto contrasta marcadamente con el caso de los modelos irracionalistas metropolitanos de Mariátegui - los representantes conceptuales (pensemos en Nietzsche, sobre todo) de una reacción social para la cual, como podríamos decir, es la historia que desde el principio hace huir a la razón. Es sólo porque Mariátegui considera a los "indios" como agentes históricos incapaces de captar su propio papel histórico en su forma racional, sólo por lo que se presume como su condición inadecuada como los sujetos teóricos de su propia objetividad histórica que Mariátegui, en última instancia, se desvía hacia lo irracional. La liberación nacional adopta la forma subjetiva y consciente del mito, pero sólo momentáneamente, sólo hasta que forma y contenido logren "cimentarse" - momento en que, teóricamente por lo menos, todo recurso al mito se vuelve históricamente superfluo. Es decir que el proyecto de la liberación nacional en ningún 
momento deja de ser, para Mariátegui, un projecto racional en su forma histórica objetiva: la "nación" en ningún momento suplanta el propósito y el contenido del proyecto de liberación en su determinación social, o sea, su aspecto de clase. Es precisamente esta integridad dialéctica, frente a lo que siempre les pareció a sus precursores en América Latina como imperativos sociales de orden metafísico o rígidamente "natural", lo que permite al pensamiento de Mariátegui la formulación de su más grande y profundamente revolucionaria idea: que la "liberación nacional" en el ambiente "postcolonial" de un Perú se vuelve una imposibilidad histórica a menos que se transforme en causa de la masa oprimida.

Nación como "alegoría", como "mito" - aquí Mariátegui ya parece anticipar una importante tendencia dentro de la teoría literaria actual, sobre todo cuando se trata de la literatura postcolonial: me refiero a la teoría de que la nación no es solamente una entidad de inescapable carácter ideológico, sino que pertenece mayor- o hasta exclusivamente al orden del discurso. La nación como "narración", de acuerdo con el título del ya conocido volumen de ensayos redactado por el crítico de la literatura postcolonial, Homi Bhabha. La nación como "comunidad imaginada" siguiendo la teoría de Benedict Anderson, o como "ficción fundacional" en la tesis de Doris Sommer sobre las raíces literarias del nacionalismo latinoamericano en el siglo XIX. ${ }^{9}$ En una variación de esta teoría -que no parece ser la predominante - la nación, por ser una especie de producto literario en sí, no resulta ser de menos valor o de menor necesidad como telos o meta de una praxis política. (Pienso aquí en el estudio de John Beverley y Marc Zimmerman ${ }^{10}$ en que se sostiene la particular eficacia de la poesía revolucionaria en Centroamérica para la creación de un nuevo sujeto nacional.) En otra variación, la nación se representa teóricamente como una forma de identidad -0 de posición de sujeto- opresiva, construida sobre una exclusión a priori de algún "otro" estigmatizado. Sommer, por ejemplo, afirma que en la Argentina como objeto de alegorización en la Amalia del ideólogo unitario José Marmol, el plebeyo mestizo o noblanco queda simbólicamente expulsado de la nación. Pero en ambas variaciones se nota un escepticismo casi absoluto hacia la estética historicista (y, en su etapa más vulgar, romanticista) que propone la literatura como valorizable en términos de algún "espíritu nacional" o Volksgeist. De acuerdo con el pensamiento post-estructuralista, y sobre todo lacaniano que es lo que más profundamente subyace a esta orientación teórica-si la potencia especial de la literatura es la de intervenir en la formación preconsciente del sujeto, laética de la litertura debe ser la de impedir que el sujeto se forme a través de una lógica del "otro". Sólo cuando la nación como tal hace el papel del "otro" (el caso de Nicaragua sandinista para Beverley y Zimmerman, por ejemplo), entonces, será lícita o positiva la idea de una literatura "nacional".

Pero ¿es a este tipo de teorización que conduce el pensamiento provisoriamente "postcolonial” y anti-eurocentrista de Mariátegui? ¿Si Mariátegui se hubiera beneficiado de las "revoluciones conceptuales" de Freud, Saussure y Derrida, nos estaría diciendo algo

\footnotetext{
${ }^{9}$ Ver Homi K. Bhabha, ed. Nation and Narration (London, NY: Routledge, 1990); Benedict Anderson Imagined Communities: Reflections on the Origin and the Spread of Nationalism (London: Verso, 1983); Doris Sommer, Foundational Fictions:the National Romances of Latin America (Berkeley, Los Angeles: University of California Press, 1991).

${ }^{10}$ Literature and Politics in Central American Revolutions (Austin: University of Texas Press, 1990).
} 
parecido -diciendo, por ejemplo, que la meta ético-social de la literatura peruana ya no debería ser la de transcender el dualismo cultural del Perú para crear una "peruanidad" autóctona, sino la de fomentar siempre una "différance" que resistiera cualquier intento de identificación reductiva? Es un poco falaz la pregunta, por supuesto, pero contestarla en forma negativa será otra manera de decir que si el pensamiento mariateguiano no se desata totalmente de un romanticismo nacionalista, tampoco se deja caer en el romanticismo subjetivista y anti-historicista del "otro", y que en este sentido no haber podido leer a Derrida y compañía puede considerarse relativamente como una ventaja. Pero lo que hay que subrayar aquí es que, a diferencia de la tendencia actual de pensar la nación como sólo una posición de sujeto entre las muchas disponibles a la literatura, Mariátegui, junto con concebir la nación como "mito" " "alegoría", no deja de insistir en el lugar social e histórico que ocupa la nación como factor integral en el proceso de la emancipación postcolonial. (Esto lleva, es cierto, a una especie de ambigüedad en el texto de "El proceso de la literatura": es así que, inmediatamente después de calificar a la nación como "mito", etc., que no es "científicamente determinable" Mariátegui, escribiendo sobre Garcilaso, habla de la "peruanidad" como "una formación social, determinada por la conquista y la colonización españolas" ("PL", 211 ; énfasis mío). La literatura, para adquirir un auténtico valor estético, tiene que ser del pueblo - y no de diferentes o de multiples pueblos cohabitando en un espacio nacional abstracto. El pueblo, universalizándose, convierte el espacio de la nación en un espacio emancipatorio, sino, por ahora, un espacio emancipado. La nación -0 algo como la nación y que no es precisamente la nación- se postula aquí, como en el hegelianismo "clásico", como el concreto universal, camino al cual, como dice la conclusión de "El proceso de la literatura", "nos vamos acercando cada vezmás a nosotros mismos"(320). Es, creo yo, la nación de que hablará Frantz Fanon, unos treinta años después de la muerte de Mariátegui, cuando escribe que

The bourgeois leaders of underdeveloped countries imprison national consciousness in sterile formalism. It is only when men and women are included on a vast scale in enlightened and fruitful work that form and body are given to that consciousness. Then the flag and the palace where sits the government cease to be the symbols of the nation. The nation deserts these brightly lit, empty shells and takes shelter in the country, where it is given life and dynamic power. The living expression of the nation is the moving consciousness of the whole of the people; it is the coherent, enlightened action of men and women. ${ }^{11}$

La nación —o la "peruanidad"- sigue siendo para Mariátegui un criterio, quizás el más alto criterio, de valor estético. Y sin embargo, la nación peruana —o "postcolonial"efectivamente no existe para Mariátegui. Lo que existe es el mito. De ahí la tarea enigmática de escribir la historia de una literatura que tampoco existe. Pero esta no-existencia, esta existencia mítica, no deja de seruna no-existencia que sí existe dentro de una dialéctica histórica. Y es porque no existe - porque su no-existencia está determinada por la sí-existencia de un

1 Frantz Fanon, The Wretched of the Earth trans. Constance Farrington (New York: Grove Weidenfeld, 1991) 204. 
sistema nacional y global de dominación capitalista e imperialista-que la "peruanidad" puede convertirse en criterio de valor estético.

En nuestra coyuntura finisecular, coyuntura en que el imperialismo parece tener campo abierto en el mundo periférico y postcolonizado, quizás resulta difícil compartir el optimismo que se encuadra en este tipo de nacionalismo. Quizás la nación que proyectaba Mariátegui se haya manifestado ya como una forma de sociedad históricamente imposible. No podemos descartar la posibilidad de que una creciente desarticulación social y cultural sea el único futuro que nos reserva el capitalismo global. Y si es así, no es difícil comprender por qué la "nación" tiende a darnos la impresión de ser una pura "narración". Pero la realidad de nuestro tiempo también parece ser tal que un escepticismo válido en cuanto a las utopías nacionalistas de la época de liberación nacional se convierte casi automáticamente en un escepticismo nihilista hacia cualquier liberación que no sea, o total y espontánea por un lado, o limitada, por otro, al plano discursivo del sujeto. Dentro de esta antinomia postmoderna caen, entre otras cosas, toda una crítica y una teoría de la literatura. Mariátegui concibió una teoría literaria "postcolonial" que todavía no conocía esta antinomia. Pero es una teoría que, por no desligar la estética de la historia, talvez nos permite ver más allá de ella. 
